\title{
JUECES CONSTITUCIONALES
}

EDWIN FIGUEROA GUTARRA*

\begin{abstract}
Resumen
El presente estudio desarrolla la importancia de una justicia constitucional del Poder Judicial a dedicación exclusiva, en atención a que el derecho es evolución y por tanto, exige especialización. Más aún, el tratamiento jurisdiccional de los derechos fundamentales exige determinadas competencias que los órganos de gobierno del Poder Judicial están en la necesidad de identificar, impulsar y consolidar. La defensa de los principios, valores y directrices que inspiran el Estado constitucional es también tarea de los jueces y es un imperativo categórico para éstos sumarse a esa tarea material.
\end{abstract}

Palabras clave: Jueces constitucionales, derechos fundamentales, justicia constitucional especializada, Tribunal Constitucional, órganos de gobierno.

\begin{abstract}
This study develops the importance of constitutional justice of the Judiciary as an exclusive task, considering that law is evolving and therefore requires expertise. Furthermore, the jurisdictional treatment of fundamental rights requires certain skills that the governing bodies of the Judiciary are in the need to identify, promote and consolidate. The defense of the principles, values and guidelines underlying the constitutional State is also the task of judges and is a categorical imperative for these ones to join such material duties.
\end{abstract}

Keywords: Constitutional judges, fundamental rights, specialized constitutional justice, Constitutional Court, governing bodies.

\section{Sumario}

1.- Introducción. 2.- Un esbozo de la noción de juez constitucional. 3.- Razones para una justicia constitucional especializada. 4.- Jueces constitucionales y órganos de gobierno. 5.- Jueces constitucionales y Tribunal Constitucional: una relación de equilibrio. 6.- ¿Todos los jueces son constitucionales? 7.- Rol relevante del Poder Judicial en la justicia constitucional especializada. 8.Efectos de la ausencia de jueces constitucionales. 9.- Casos especiales de justicia constitucional especializada. 10.- Una visión de los jueces constitucionales en el Derecho Comparado. 11.- A modo de conclusión. 12.-Referencias bibliográficas.

\footnotetext{
* Doctor en Derecho. juez superior titular de la Corte Superior de Justicia de Lambayeque - Perú. Profesor asociado de la Academia de la Magistratura del Perú. Docente área constitucional de la Universidad San Martín de Porres, filial Chiclayo, Lambayeque-Perú.
} 


\section{Introducción}

En su famoso mito de la caverna, Platón hacía importante referencia al mundo de las ideas y del conocimiento y planteaba sacudirse del yugo de las sombras para optar por la luz del conocimiento, la reflexión y el análisis. La labor judicial presenta algunos caracteres similares con la alegoría platónica. La principal tarea del Poder Judicial- impartir justicia en condiciones de igualdad y en el marco de respeto por la ley y la Constitución- es despejar las sombras de interpretación jurídica que caracterizan los procesos judiciales, siempre atendiendo a que dos partes en conflicto sostienen posiciones contrarias, y reafirmar la existencia del Estado de Derecho impartiendo la luz de la interpretación más ajustada a nuestra Carta Fundamental en defensa de sus principios.

En ese mismo sentido, la labor de los jueces constitucionales representa un plus de exigencia, pues no solo les compete el deber de protección de los derechos que prima como valor representativo en la justicia ordinaria, sino les atañe un deber especial de protección, es decir, un deber reforzado de tutela de los derechos fundamentales. Embarcarnos en la naturaleza especial de esa compleja tarea es un deber parecido al del juez Hércules de Dworkin, pues se encuentra de por medio una tarea calificada de protección de los derechos fundamentales y esto denota exigencias de competencia, conocimiento y formación especiales.

Construimos así la tesis de este breve estudio en el sentido de la importancia, exigencia y necesidad de construir una justicia constitucional especializada, con jueces del Poder Judicial a dedicación exclusiva para la resolución de controversias constitucionales, al tratarse de un imperativo categórico que fijan los valores constitucionales. Esta tarea demanda de la propia Administración, igualmente, en propiedad de los órganos de gobierno del Poder Judicial, una labor de examen trascendente para definir una justicia constitucional especializada, pues el rol que le compete a estos órganos de dirección del corpus iuris, precisamente involucra que la creación de una justicia constitucional a tiempo completo se materializa en la existencia de un Estado constitucional que fija la tareas, obligaciones y deberes que demandan igualmente una visión de conjunto de los problemas del ordenamiento jurídico y no una labor solo nominal de dirección de la problemática judicial.

Es importante anotar que la dedicación a exclusividad en el ámbito constitucional existe en nuestro país: a nivel de los magistrados del Tribunal Constitucional, de un lado, y en forma parcial, a nivel del Poder Judicial. Existen algunos juzgados constitucionales en nuestro país y su impulso se dio desde 2006, avanzándose en el camino con la creación de nuevos órganos jurisdiccionales a dedicación exclusiva, pero las políticas públicas del año 2014 en los órganos de gobierno del Poder Judicial, arrojaron un balance de restricción vía la reconversión de órganos constitucionales a 
laborales, con lo cual se restringió severamente la expansión de la justicia constitucional especializada.

Este estudio plantea la restitución de los órganos constitucionales desactivados, resaltando antes la importancia de una justicia constitucional a dedicación exclusiva en los jueces del Poder Judicial y que los avances generados, no sean dejados sin efecto, o más aún, que se restrinja aún más la justicia constitucional hasta ahora en parte consolidada en pocos juzgados constitucionales. Por el contrario, los beneficios de una justicia iusfundamental a dedicación exclusiva, pueden reportar efectos colateralmente positivos si su práctica se extiende a la justicia ordinaria, y con ello nos referimos a varias de las figuras que identifican la lógica de los procesos constitucionales, las cuales se traducen en celeridad procesal, tutela de urgencia, racionalidad de los procesos, entre otros temas puntuales que identifican la impartición de justicia constitucional.

\section{Un esbozo de la noción de juez constitucional}

Confrontar los conceptos de jurisdicción y competencia resulta siempre una tarea apasionante pues a pesar de la cercanía conceptual de ambos significados, existen notorias diferencias que anotar, lo cual implica una aproximación a su contenido semántico. Todos los jueces tienen jurisdicción pero no todos competencia y en ese aspecto, nuestra fuente normativa nacional ha consolidado la existencia de jueces constitucionales, competentes para conocer los procesos de la libertad.

Solemos decir, a modo de parafraseo, que todos los jueces son constitucionales y que por tanto, no existe la necesidad de una especialización de los mismos, y sin embargo, la experiencia de campo en el caso nacional refleja la necesidad de desarrollar competencias constitucionales propias y a este efecto, la experiencia peruana exhibe, aunque con idas y venidas y en forma parcial, un desarrollo singular, importante y de especialización en materia constitucional, aunque caracterizada, como anotamos, por marchas y contramarchas ${ }^{1}$.

La jurisdicción constitucional peruana, como señalamos supra, bifurca sus contenidos en dos grandes áreas: de un lado, la competencia propia de los jueces del Poder Judicial, los cuales asumen la responsabilidad de constituirse en los primeros bastiones de defensa de los derechos fundamentales, en primer y segundo nivel, tarea que se delega actualmente a juzgados y Salas, civiles y penales; ${ }^{2}$ y de otro lado, la

1 Acotamos esta característica pues nuestros órganos de gobierno en el Poder Judicial optaron, en una primera etapa, por la creación de juzgados y Salas Constitucionales, a dedicación exclusiva, y luego en propiedad, vía reconversión de competencias, se desactivaron gran parte de los órganos creados, principalmente en los últimos años.

2 Esto sucede en casi todas las Cortes de Justicia del país, salvo en Lima, que alberga 11 juzgados constitucionales. El resto del país delega las competencias constitucionales a jueces y Salas Civiles. No 
competencia asignada al propio Tribunal Constitucional, órgano que revisa en última instancia los procesos constitucionales de la libertad denegatorios, y a su vez, conoce los procesos de control normativo en instancia única, en rigor los procesos de inconstitucionalidad y competencial.

La figura descrita, sin embargo, presenta un punto de quiebre sustantivo: los jueces del Poder Judicial que revisan procesos constitucionales son, en su mayoría, de la especialidad civil, quienes en adición a sus funciones, conocen también procesos constitucionales. Son 11 juzgados constitucionales los que existen en la ciudad capital $^{3}$, los cuales se dedican exclusivamente a conocer estos procesos de la libertad, y lo hacen solo circunscritos a los procesos de amparo, cumplimiento y habeas data, en tanto que solo los jueces penales son competentes para conocer los procesos de habeas corpus. En el resto del país, casi no existen juzgados constitucionales ni Salas Constitucionales, quedando encomendada la tarea de resolver estos casos a la justicia civil.

Frente a este escenario, nuestro Código Procesal Constitucional esboza ya una aproximación a la noción de juez constitucional ${ }^{4}$, y parte de la tesis de una labor especializada para el conocimiento de las controversias constitucionales. Este perfil es necesario, a juicio nuestro, pues las controversias que atañen a derechos fundamentales, demandan competencias especializadas para discernir cuando un acto supuestamente lesivo agravia o no en forma ilegítima los derechos tutelados por la Carta Fundamental.

Más aún, el juez constitucional "mira más allá", en acertada expresión de Gustavo Zagrebelsky, ${ }^{5}$ para hacer valer los derechos fundamentales sobre la senda de las convenciones, declaraciones y documentos de matriz internacional en relación con la persona humana como tal. Por tanto, recae sobre los hombros del juez constitucional definir el contenido de moralidad de los derechos en pugna, y también para determinar la restitución propia del caso ante una agresión manifiesta a un derecho fundamental.

obstante su importancia, es especialidad constitucional es solo una competencia más de la justicia civil en casi todo el país.

3 Por Res. Adm. № 206-2012-CE/PJ, de fecha 24 de octubre de 2014, se creó el 11 Juzgado Constitucional con subespecialidad en temas tributarios y aduaneros en la Corte Superior de Justicia de Lima.

4 Código Procesal Constitucional Perú (2004) Tercera disposición final. Jueces Especializados Los procesos de competencia del Poder Judicial a que se refiere el presente Código se iniciarán ante los jueces especializados que correspondan en aquellos distritos judiciales que cuenten con ellos, con la sola excepción del proceso de hábeas corpus que podrá iniciarse ante cualquier juez penal.

5 ZAGREBELSKY, Gustavo. ¿Qué es ser juez constitucional?, en https:/ / dialnet.unirioja.es/descarga/articulo/2292042.pdf, consulta: 07 de abril de 2016. 


\section{Razones para una justicia constitucional especializada}

La premisa de la cual parte el enfoque de este estudio, es la necesidad de consolidar una justicia constitucional especializada, que otorgue competencias específicas a los jueces en materia constitucional y que puedan asignarles el conocimiento exclusivo de los procesos constitucionales de la libertad. Si bien esta premisa ya se cumple parcialmente en el país, creemos que es necesaria su consolidación como política pública respecto al corpus iuris, y no su restricción.

Las razones para la viabilidad de este planteamiento son varias: en un primer plano, la especialidad constitucional sí es necesaria pues los jueces civiles parten, usualmente, de patrones de interpretación distintos, en relación a los de la justicia ordinaria, y no necesariamente aplican cánones de interpretación constitucional, la cual se caracteriza por el influjo propio que emana de los procesos constitucionales de la libertad. En principio, no hemos de dudar de las calidades de un juez civil para dirimir una colisión entre derechos fundamentales y sin embargo, es exigible una especialización de rigor en el esclarecimiento de controversias iusfundamentales.

Otra razón que corrobora este aserto es que, en propiedad, se justifica una justicia constitucional especializada, pues de igual forma a como existen jueces penales, civiles, laborales y de otras especialidades, es necesario, también, que existan jueces constitucionales a dedicación exclusiva. La razón de esta segunda justificación de peso es que el conocimiento de los procesos constitucionales de la libertad, demanda competencias especiales como el manejo directo de la vulneración misma, su extensión y significado, o discernir respecto a la omisión gravosa, a fin de determinar su legitimidad o ilegitimidad, prescindiéndose, por tanto, de la necesaria etapa probatoria ${ }^{6}$, de la cual sí gozan los procesos ordinarios. Por tanto, es necesario discernir con las solas pruebas documentarias aportadas por las partes si se agravió o no ostensiblemente un derecho fundamental, no existiendo un rigor una formal etapa probatoria.

Notemos acá una diferencia sustantiva y de rango extraordinario entre los procesos ordinarios y los procesos constitucionales, en tanto los procesos iusfundamentales no presentan un examen riguroso de tránsito de diversos tipos de medios probatorios, en razón de que le conceden a la prueba documentaria y no a otro tipo de pruebas, la excepcional tarea de probar por sí misma la agresión constitucional que se denuncia. Por tanto, es importante manejar un conjunto de competencias especiales para manejar un activismo judicial que no podrá ser desmedido, sino por el contrario,

6 Código Procesal Constitucional. Artículo 9.- Ausencia de etapa probatoria

En los procesos constitucionales no existe etapa probatoria. solo son procedentes los medios probatorios que no requieren actuación, lo que no impide la realización de las actuaciones probatorias que el Juez considere indispensables, sin afectar la duración del proceso. En este último caso no se requerirá notificación previa. 
cauto, ponderado y equilibrado, y más cercano ciertamente de las tendencias interpretativas que caracterizan a los derechos fundamentales.

Más aún, mientras el enfoque básico central de la justicia ordinaria es sustantiva aunque no exclusivamente local, pues debe partir prevalentemente de bases normativas de rango nacional, el examen de las controversias iusfundamentales suele aterrizar, muchas veces, en las posiciones de examen de la Corte Interamericana de Derechos Humanos, la cual fija estándares que vinculan a los Estados parte, así como es importante apreciar en este campo la evolución de derechos especialísimos en órganos jurisdiccionales de relevancia como el Tribunal Europeo de Derechos Humanos y el Tribunal Constitucional español, elementos que conceden un marco de referencia que a pesar del margen de apreciación que algunas veces esas altas Cortes admiten en su interpretación, en buena cuenta implican una determinación en el sentido que no pueden soslayarse sus estándares en la valoración de una causa que atañe a derechos fundamentales.

Una tercera razón de peso para una justicia constitucional especializada está representada, igualmente, por el conjunto de exigencias que plantea el mismo concepto de Estado constitucional, bajo la siguiente reflexión: para la defensa de los derechos fundamentales en el Estado constitucional, es exigible, razonable y ponderado que existan jueces constitucionales a dedicación exclusiva, cuya tarea se oriente a un profundo conocimiento de las condiciones, exigencias y estándares que plantea el desarrollo de los derechos fundamentales. Es así que podemos construir el razonamiento de que no hay Estado constitucional sin jueces constitucionales, pues a estos está asignada la labor de constituir baluartes de la defensa del contenido constitucionalmente protegido de los derechos fundamentales.

En cuarto lugar, la justicia constitucional ostenta caracteres muy especiales, diferentes a los de la justicia ordinaria, justificando así la existencia de una justicia de los derechos fundamentales. Siguiendo a Zagrebelsky, ${ }^{7}$ podemos entender su aserto de que "la razón de ser de la justicia constitucional es su función antimayoría (...) por eso podemos afirmar que la justicia constitucional no forma parte de la democracia pero sirve a la democracia".

En efecto, desde el Federalista 78,8 de Hamilton., Jay y Madison, asumimos ciertamente el carácter antimayoritario de las decisiones de los jueces, pues existe una labor correctora de las decisiones de los demás poderes, entre ellos el Poder Legislativo, un ente que representa la decisión de las mayorías. Por consiguiente, es necesario que el juez constitucional asuma la perspectiva de que forma parte del

7 ZAGReBelSKY, Gustavo. (2008) Principios y votos. El Tribunal Constitucional y la politica. Traducción de Manuel Martínez Neira. España. Mínima Trotta, p. 102.

8 GARGARELLA, Roberto (1997). La dificultad de defender el control constitucional de las leyes. Isonomía. No. 6, abril, p.55. 
Estado de Derecho, mas sus decisiones no siguen un patrón estrictamente democrático, pues no proviene su elección de mandato popular, y sin perjuicio de ello, sirve a la democracia y sus principios. Por tanto, esa calidad de juez constitucional implica un acatamiento a la Constitución pero cual oxymoron, no proviene ese nombramiento de las propias mayorías, sino en rigor ejerce ese juez constitucional una función de legitimación de la Constitución.

¿Quién puede desarrollar esa labor compleja con mejores posibilidades de discernir razonablemente entre las tendencias antimayoritarias? Creemos que un juez constitucional a dedicación exclusiva.

En esa misma línea de ideas, se justifica la existencia de un "derecho constitucional abierto",9 reflexión aportada por Zagrebelsky, en oposición igualmente a la impotencia de un Derecho Constitucional cerrado, precisamente porque se trata de dos variantes relevantes de la interpretación. Bajo las pautas de un Derecho Constitucional abierto se ciñe una interpretación de principios, valores y directrices, aquello que denominamos un ámbito material de la interpretación, en tanto que involucra un Derecho Constitucional cerrado aquel cuya campo de acción es un ámbito más formal, de subsunciones y silogismos. En consecuencia, demanda una tarea más rigurosa atender a los sentidos interpretativos de la norma, buscando el necesario examen de compatibilidad con la Constitución, antes que quedarnos a medio camino en una simple lectura del enunciado lingüístico de la disposición.

No queremos atribuir aquí, nuevamente, que un ámbito sea atribución de la justicia ordinaria y el otro de la justicia constitucional. Superan los jueces ordinarios, por cierto, y muchas veces, el mero examen de formalidad de las reglas. Esta es una premisa que viene trabajando, con intensidad el corpus iuris judicial en todos sus ámbitos, pero volvemos en toda su extensión al mismo concepto: los jueces constitucionales a dedicación exclusiva desarrollan, en mejor posición, ese ámbito de moralidad de los derechos fundamentales, cuyo valor axiológico no es enunciado con sencillez, y muchas veces tampoco aceptado, por la justicia ordinaria.

Y son así los jueces constitucionales quienes desde Evans Hughes, magistrado de la Corte Suprema de EE.UU., logran expresar aquello que significa la Constitución. Por eso es válida la afirmación de Hughes quien expresa: "Nos regimos por una Constitución, pero la Constitución es lo que los jueces dicen que es". ${ }^{10}$ La figura es clara: son los jueces, del Tribunal Constitucional y del Poder Judicial, quienes dicen

9 ZAGREBELSKY, Gustavo. (2008). El juez constitucional en el siglo XXI. Ponencia presentada en el I Congreso Internacional de Justicia Constitucional y V Encuentro Iberoamericano de Derecho Procesal Constitucional, celebrado en Cancún, México, del 14 al 17 de mayo de 2008. Revista Iberoamericana de Derecho Procesal Constitucional núm. 10, julio-diciembre 2008, pp. 249-268. p. 255.

10 HARO, Ricardo. El control de constitucionalidad comparado y el rol paradigmático de las cortes y tribunales constitucionales. En Anuario de Derecho Constitucional Latinoamericano, n. 20041, 2004, pág. 62. 
cuál es el contenido material de la propia Constitución. Las interpretaciones de arraigo, vinculación y prevalencia, por consiguiente, van a estar del lado de jueces constitucionales antes que de jueces de la jurisdicción ordinaria.

\section{Jueces constitucionales y órganos de gobierno}

¿Qué deben hacer los órganos de gobierno judicial frente a la relevancia de la justicia constitucional y sus exigencias? A juicio nuestro, identificar, en primer lugar, la importancia de la dimensión de una justicia especial constitucionalizada propia del Poder Judicial, que construya estándares de protección de los derechos fundamentales, y proceder, como ya se ha hecho de modo parcial, aunque con idas y venidas, a crear, extender y reforzar la existencia de jueces constitucionales especializados, y Salas Constitucionales igualmente especializadas, pues esta es la premisa de orden más equilibrada dentro del concepto de elaboración de un verdadero esquema de vigencia efectiva de los derechos fundamentales en el Estado constitucional.

En adición a ello y como un problema propio de nuestra realidad y su ingente carga procesal, ¿qué hacer si el crecimiento de las exigencias de la justicia ordinaria obliga a que se dedique todo el esfuerzo posible de los jueces a pretender reducir esta carga procesal abrumadora? Pues no reconvertir en propiedad órganos constitucionales existentes, o de otra naturaleza análoga,11 sino precisamente reforzar competencias constitucionales para que desde la necesaria simbiosis que implica el trabajo de los jueces constitucionales y las exigencias de la impartición pronta, clara y residual de justicia especializada, se creen las condiciones especiales del caso para una reducción de la carga procesal. Propiamente sostenemos aquí que la práctica constitucional precisamente aporta estándares muy sui géneris que justifican plenamente su existencia y más aún, desde una cultura judicial de refuerzos, las prácticas positivas de los jueces constitucionales, bien pueden trasladarse, con las variantes del caso, a la justicia ordinaria.

La afirmación nuestra que antecede no es abstracta y por el contrario, es meridianamente contributiva de contextos más complejos, entre los cuales destaca la

11 En los últimos años un importante número de órganos jurisdiccionales han sido reconvertidos de sus diversas especialidades para atender la carga procesal de los juzgados y Salas Laborales, en respuesta a la exigencia de resolución de una cantidad importante de procesos, principalmente por la congestión de procesos en materia laboral. La reflexión a este respecto es si se da solución a un problema material o a un problema nominal. La numerosa cantidad de procesos laborales es ante todo un problema nominal, a juicio nuestro, pues muchas controversias resultan muy similares en materia laboral, con soluciones muy parecidas, aspecto que no justifica, como medida de fondo, la reconversión de otros órganos jurisdiccionales no laborales. Por el contrario, exige una política pública de mayor alcance como un tratamiento más estratégico de la carga procesal: cerrar el acceso de casos muy similares a la Corte Suprema si ya hubo doble instancia, conceder facultad de cierre de las controversias laborales a órganos de segunda instancia, declarar el estado de cosas inconstitucional para reducir el número de procesos, entre otras alternativas. etcétera. 
exigencia de una justicia constitucional especializada y sus prácticas relevantes en la tutela de urgencia, lo mismo que se traduce en un conjunto de criterios para una pronta impartición de justicia de los derechos fundamentales. Si eventualmente existe una buena práctica constitucional especializada, no apreciamos inconveniente alguno en que esas buenas prácticas se trasladen, con los ajustes del caso, a la justicia ordinaria.

De esta forma, es una primera característica especial de la justicia constitucional especializada la tesis de la sentencia estimatoria de segunda instancia como medio de fin del conflicto, constituyendo una regla relevante. En efecto, si una sentencia de segunda instancia en un proceso constitucional es declarada fundada, el proceso propiamente dicho ya concluyó, siempre que nos refiramos a la materia constitucional ${ }^{12}$, dado que el Tribunal Constitucional solo conoce fallos denegatorios.

El debate, en el caso arriba expuesto, llega a su término pues ya la parte afectada logró una decisión que le favorece y esto traduce una regla de racionalidad y razonabilidad, pues la discusión ya no se extiende más en otra instancia ${ }^{13}$. Esto no necesariamente sucede en la justicia ordinaria pues de distintas formas, al ser viable un recurso de casación y por ende que el caso pueda acceder a la Corte Suprema, lo que se produce es una congestión de causas ante la Corte misma, y por lo tanto, se desprende de ello la necesidad de ir creando más órganos jurisdiccionales, respuesta a juicio nuestro lineal y no de orden material, es decir, no es propia de un contexto material de trascendencia, esto es, se soluciona parcialmente los efectos del problema mas no el problema propiamente dicho.

Otra segunda característica especial es en definitiva la posibilidad de que el estado de cosas inconstitucional ${ }^{14}$ constituya una figura propia de expansión de efectos de la sentencia. Veámoslo a través de un ejemplo muy sencillo. Si tenemos 100 casos concluidos muy similares, es natural, racional y consecuentemente lógico que tengamos 100 demandas, 100 contestaciones, 100 sentencias, 100 apelaciones, 100 fallos de segunda instancia, 100 recursos de casación cuando corresponda, y 100 decisiones distintas de la Corte Suprema.

12 El artículo 202 de la Constitución señala queel Tribunal Constitucional conoce solo sentencias denegatorias en procesos de la libertad. En vía de referencia, las sentencias estimatorias en segunda instancia en materia constitucional, implican la conclusión de la controversia, sin posibilidad de acceso del caso al Tribunal Constitucional, salvo las habidas excepciones de casos vinculados al narcotráfico, lavado de activos y terrorismo. Vid STC 01711-2014-PHC/TC, caso Víctor Polay Campos, fundamento jurídico 7.

13 Excepción habida del amparo contra amparo según los alcances de la STC 4853-2004-AA/TC, caso Dirección Regional de Pesquería de La Libertad, fundamento jurídico 39.

14 Figura creada por la Corte Constitucional de Colombia en 1997, noción que a su vez puede ser entendida como expansión de los efectos de la sentencia. Vid en Perú la STC 2579-2003-HD/TC caso Julia Arellano, fundamentos jurídicos 18-23. 
¿Qué pasa si invertimos la figura, siempre en el supuesto de 100 pretensiones similares., en desarrollo de la figura del estado de cosas inconstitucional, y por el contrario, tenemos solo un caso paradigmático en el cual se definen las condiciones especiales del caso y al mismo concurren las restantes 99 pretensiones, en ejecución de sentencia, solo para solicitar se haga efectiva su prestación demandada, sin transitar por las demás etapas del proceso?

La justificación de esta posición, desde la perspectiva de la Corte Constitucional de Colombia, ente que generó este concepto procesal constitucional en 1997, obedecía a la idea de que no se produjera un innecesario debate de causas sustantivamente similares y por el contrario, se racionalizara de algún modo el acceso a la justicia.

En el mismo caso en comento, 99 peticiones de ejecución directa de la prestación podrían concurrir al caso paradigmático, y previa valoración del juez constitucional respecto a la naturaleza de la pretensión y sobre todo de su viabilidad por similitud con el caso paradigmático, este despacharía ejecución sobre la base de que la pretensión es sustantivamente similar a la del caso base. El principio de pluralidad de instancias quedaría plenamente garantizado pues si la parte emplazada considerara que su derecho se ve afectado, puede recurrir vía apelación, sin efecto suspensivo, es decir, sin suspender la marcha del proceso respecto a la nueva pretensión incoada, ante la Sala Superior, para que esta defina lo que corresponde de acuerdo a ley y derecho. Por cierto, de darse esta figura, ya podríamos apreciar una reducción considerable de la carga procesal potencialmente alta del actual sistema de justicia no solo constitucional, vía la adopción de mecanismos innovadores, sino también a nivel de la justicia ordinaria.

Salas Superiores y Salas Supremas tendrían la opción de declarar el estado de cosas inconstitucional y vía parámetros trabajados ante los órganos de control y con la necesaria difusión de la figura ante los Colegios de Abogados del país, se darían las condiciones óptimas del caso para pretender una reducción sustantiva de la carga procesal que hoy abruma los órganos jurisdiccionales del país, y que en verdad demanda de los órganos de dirección del Poder Judicial, adoptar ideas efectivamente directrices de políticas de reducción del número de procesos que hoy debe manejar el corpus iuris.

Por tanto, adoptada esta figura en diversos casos de la realidad constitucional peruana $^{15}$, su mayor difusión a nivel de órganos jurisdiccionales constitucionales,

15 Vid STC 05561-2007-PA/TC, caso ONP, sobre participación temeraria, obstructiva y contraria a la jurisprudencia y precedentes de este Tribunal de la ONP en los procesos judiciales relacionados a los derechos pensionarios que administra; y STC 3426-2008.PHC/TC, caso Pedro Marroquín, sobre la falta de una política de tratamiento y rehabilitación de la salud mental de personas que se encuentran sujetas a medidas de seguridad de internación por padecer de una enfermedad mental. 
indudablemente tendría un efecto de sana réplica a nivel de la justicia ordinaria. ¿Es posible visualizar un Poder Judicial con menor carga procesal? Creemos que sí.

También se manifiesta otra característica especial, propia de los órganos constitucionales, en una estrategia propia de sede constitucional cual es la figura de represión de actos homogéneos, ${ }^{16}$ medio de defensa que permite que ante una nueva agresión similar a aquella que se produjo en las sentencias que restituye el derecho afectado, ya no haya necesidad de recurrir a otro y nuevo proceso judicial, sino que sea en el mismo proceso constitucional donde, en ejecución de sentencia, se determine que existe una nueva agresión iusfundamental y que por tanto, se inste a respetar el derecho que es materia de afectación.

¿Cuál es el beneficio potencial? Pues evitar un nuevo proceso y restituir igualmente el derecho conculcado. Notemos aquí algo objetivo: se trata de herramientas procedimentales que explican una justicia más célere, más pronta y más acorde con la tesis de un recurso sencillo y rápido para el esclarecimiento de controversia que afectan derechos fundamentales, conforme fluye de la noción de protección judicial que enuncia el artículo $25^{17}$ de la Convención Americana de Derechos Humanos.

Hemos referido, solo a grandes rasgos, algunas de estas características especiales de los procesos constitucionales, las mismas que representan un punto de quiebre en relación a la noción formal de justicia ordinaria, la cual tiende, creemos, a ser respetuosa de las reglas que ordenan los procesos judiciales pero que no siempre identifican, salvo casos muy especiales, ${ }^{18}$ la necesidad de discernir entre lo urgente y lo que muchas veces entendemos como una observancia escrupulosa de las formas procesales, no siendo relevante si ello crea condiciones de afectación material. Estas características especiales justifican, de suyo, la existencia de un juez constitucional

16 Código Procesal Constitucional. Artículo 60. Procedimiento para represión de actos homogéneos

Si sobreviniera un acto sustancialmente homogéneo al declarado lesivo en un proceso de amparo, podrá ser denunciado por la parte interesada ante el juez de ejecución. Efectuado el reclamo, el Juez resolverá este con previo traslado a la otra parte por el plazo de tres días. La resolución es apelable sin efecto suspensivo. La decisión que declara la homogeneidad amplía el ámbito de protección del amparo, incorporando y ordenando la represión del acto represivo sobreviniente.

17 Convención Americana de Derechos Humanos. Artículo 25. Protección Judicial

1. Toda persona tiene derecho a un recurso sencillo y rápido o a cualquier otro recurso efectivo ante los jueces o tribunales competentes, que la ampare contra actos que violen sus derechos fundamentales reconocidos por la Constitución, la ley o la presente Convención, aun cuando tal violación sea cometida por personas que actúen en ejercicio de sus funciones oficiales.(...)

18 La tutela de derechos es un mecanismo que prevé una respuesta intraproceso respecto a la afectación de un derecho fundamental. El Código Procesal Penal de Perú prevé en su artículo 71.4 lo siguiente:

4. Cuando el imputado considere que durante las Diligencias Preliminares o en la Investigación Preparatoria no se ha dado cumplimiento a estas disposiciones, o que sus derechos no son respetados, o que es objeto de medidas limitativas de derechos indebidas o de requerimientos ilegales, puede acudir en vía de tutela al Juez de la Investigación Preparatoria para que subsane la omisión o dicte las medidas de corrección o de protección que correspondan. La solicitud del imputado se resolverá inmediatamente, previa constatación de los hechos y realización de una audiencia con intervención de las partes. 
especializado, cuyas prácticas de defensa de los derechos fundamentales, deben lograr un nivel de consolidación en el mismo Poder Judicial para de ahí trasladar esas buenas prácticas en el modo que corresponda a la justicia ordinaria.

El establecimiento de órganos constitucionales especializados en definitiva apunta, también, a la consolidación de una nueva cultura judicial, a la formación de nuevos patrones de dirección y resolución del proceso y a una respuesta más célere ante las afectaciones sustantivas a los derechos fundamentales. Por tanto, es una exigencia material la existencia de jueces constitucionales a dedicación exclusiva y es tarea de los órganos de gobierno del Poder Judicial determinar su promoción y no su exclusión.

\section{Jueces constitucionales y Tribunal Constitucional: una relación de equilibrio}

En el ejercicio de defensa de la Constitución, la existencia de jueces constitucionales especializados se orienta a mantener una buena relación de coordinación, de tendido de puentes y de conciliación, con la labor interpretativa del Tribunal Constitucional, antes que de separación estricta de las potestades de interpretación de estos estamentos constitucionales.

La justificación es sencilla: los jueces constitucionales identifican, muchas veces, bolsones de afectación de sus facultades de interpretación de la ley ordinaria y la Constitución, siendo la labor interpretativa del Tribunal prevalentemente correctora. Y ciertamente algunas veces parecen los jueces haberse convertido en la boca del Tribunal Constitucional cuando antes fueron, en los albores de la Revolución Francesa, la boca de la ley. Es pertinente anotar, por tanto, que estas nociones marcan una tarea de exclusión y caminos divergentes antes que de conciliación de materias de interpretación. Sin embargo, ello no debe ser así.

El camino interpretativo de los jueces del Poder Judicial ante las potestades de definición de los sentidos interpretativos que asigna el Tribunal Constitucional a las reglas, normas y hechos, se caracteriza por la asignación de una condición de prevalencia a los fallos constitucionales, la misma que no solo es reconocida por la Constitución de 1993 y la Ley Orgánica del propio Tribunal, sino por una jurisprudencia propia y comparada cuyo camino se desbroza por asignar a los jueces una vigencia de su interpretación siempre que no contradiga los estándares propios que fija el guardián de la Constitución, en este caso, el propio Tribunal.

Fijada esa condición, no habrá de ocurrir que la creación de órganos jurisdiccionales especializados en materia constitucional haya de significar espacios de interpretación que vaya ganando el Tribunal Constitucional para sí mismo, ni que pueda este alto Tribunal quizá identificar órganos jurisdiccionales afines a su tarea de impartición de justicia constitucional, o bien que el Poder Judicial se "constitucionalice" en desmedro 
de la autonomía e independencia del propio Poder Judicial, sino que habrá que ceñirnos a una perspectiva de legitimación de la Constitución en el ejercicio de esa labor correctora del Tribunal Constitucional cuando este enmienda decisiones del Poder Judicial, incluidas sentencias de la misma Corte Suprema.

Por tanto, sí creemos que el aserto más razonable al respecto no se dirige a poner a un poder por encima de otro, sino de asumir que una labor de interpretación de la Constitución implica aceptar una labor correctora, la cual exige estándares de unidad, concordancia práctica, corrección funcional, función integradora y primacía normativa de la Constitución. Estos aspectos no son pues sino elementos coadyuvantes que comparten jueces del Poder Judicial y Tribunal Constitucional en la dilucidación de los casos sometidos a su conocimiento.

\section{6. ¿Todos los jueces son constitucionales?}

¿Por qué deben existir jueces constitucionales a dedicación exclusiva si un aserto famoso nos dice que todos los jueces son constitucionales? ${ }^{19}$ En efecto, bien podríamos decir que por ser todos los jueces defensores de la Constitución, entonces ya no deviene necesaria una justicia constitucional especializada.

La frase que aludimos parte de una reflexión en realidad sostenidamente simple. Es cierto que todos los jueces son defensores de la Constitución antes que de las disciplinas propias del Derecho. Así, un juez penal es ciertamente un juez que debe estar imbuido de los principios y valores que emanan de la Norma de Normas, antes que los lineamientos formales y materiales que impone el propio Derecho Penal.

Más aún, no puede resolver ese juez penal una controversia propia de su materia sin antes prever las máximas constitucionales que identifican el proceso penal, y sin embargo, es cierto también que el diseño de la justicia constitucional demanda calidades, competencias y un acuerdo de procedimientos propios para resolver un tipo de procesos que no sigue necesariamente los patrones de la justicia ordinaria, sino que por el contrario, induce a consolidar un conjunto de principios, formales y materiales, para el esclarecimiento de controversias constitucionales.

De otro lado, la existencia de una justicia constitucional especializada no hace sino seguir una lógica de desarrollo contextual del Derecho, como disciplina que aspira a nuevos estándares de comprensión en el ordenamiento jurídico contemporáneo. Así como ha ocurrido que el Derecho Penal, Civil y Laboral se han convertido en

19 La Corte Constitucional de Colombia señala en el auto 145/06, de fecha 09 de mayo de 2006, caso conflicto de competencia entre la Sala Penal del Tribunal Superior de Medellín y el Juzgado Civil del Circuito de Envigado, Antioquia, lo siguiente:

3. (...) Bajo el orden constitucional vigente, reitera la Corte, todos los jueces de la República son jueces constitucionales; las especialidades de cada funcionario judicial, propias de la jurisdicción ordinaria, no son relevantes para establecer la competencia en materia de tutela. 
disciplinas autónomas, que a su vez han dado lugar a jueces autónomos en las áreas que son propias de estas disciplinas, de igual forma la exigencia de razonabilidad de existencia de jueces constitucionales especializados, cae por su propio peso cuando observamos escenarios de afectación de los derechos fundamentales.

\section{Rol relevante del Poder Judicial en la justicia constitucional especializada}

Tiene significado material una tarea de concordancia de la interpretación constitucional de los jueces del Poder Judicial con aquella que perfila el Tribunal Constitucional. Si ello es así y el Poder Judicial asume una posición activista en su interpretación, creemos que ha de ser menor la labor correctora del propia Tribunal Constitucional respecto a decisiones en materia constitucional y de justicia ordinaria del Poder Judicial.

Reiteremos la idea: una competencia estructural de los jueces constitucionales a dedicación exclusiva evitará incluso una mayor carga al Tribunal Constitucional. En efecto, si observamos que la carga del Tribunal Constitucional se ha ido incrementando, aunque con intermitencias, en los últimos años, ${ }^{20}$ hay dos posibles consecuencias: de un lado, una mayor población exige una mayor infraestructura de los órganos jurisdiccionales; y en un segundo plano, si la cultura de litigiosidad de nuestra sociedad sigue un camino in crescendo, entonces se ha de producir lógicamente un mayor número de procesos.

Las dos justificaciones que presentamos pueden concurrir en forma conjunta en tanto constituyen explicaciones fiables respecto del problema que presentamos. Mas en este escenario destaca un tercer ángulo: si los jueces constitucionales manejan mejor los patrones de interpretación constitucional que les deben ser propios en su tarea de impartir justicia, es más altamente probable que han de generarse sentencias estimatorias en los casos en que corresponda, por cierto en mayor número, y por tanto, disminuya la carga de procesos a conocer por parte del Tribunal Constitucional, asumiendo, claro está, que en la justicia constitucional los procesos constitucionales concluyen si existe sentencia estimatoria de segunda instancia.

Veámoslo con cifras aproximadas: si de un total de 100 procesos constitucionales ante el Poder Judicial, y nos referimos a estándares genéricos, 30 de ellos merecen sentencia estimatoria y 70, pronunciamiento denegatorio, ello quiere decir que un $70 \%$ de la carga del Poder Judicial en materia constitucional llega al alto Tribunal. A su vez, si de esos 70 procesos, igualmente un $30 \%$ de procesos logra pronunciamiento estimatorio (es decir 21 procesos más) ante el Tribunal Constitucional, siempre en cifras aproximadas, ello querrá decir que 49 procesos habrán de seguir mereciendo decisión denegatoria por parte del Tribunal, frente a 51 procesos ya concluidos ante el

20 Según Memoria del Tribunal Constitucional, 2014, p. 83, la carga del Tribunal en el año 2012 fue de 5286 expedientes ingresados; en el año 2013, de 8863 expedientes; y en el año 2014, de 6432 expedientes. 
Poder Judicial. Los números son claros: a mayor involucramiento de la interpretación constitucional de los jueces del Poder Judicial, menos procesos han de llegar al Tribunal Constitucional.

Nuestro planteamiento solo pretende referir, en resumen, que si disponemos de una justicia constitucional especializada, es altamente probable que más procesos constitucionales concluyan en el Poder Judicial y así se reduzca la carga del Tribunal Constitucional. ¿Por qué? Porque en el ejemplo que ponemos supra, es altamente probable que si sumamos como sentencias estimatorias esos 21 procesos más arriba referidos (aquellos que hayan subido al Tribunal y hayan merecido sentencia estimatoria), suba la media de acierto aproximada del Poder Judicial respecto a los procesos constitucionales, a un total de 51 procesos, con lo cual una carga aún menor podrá ser la que conozca el Tribunal Constitucional.

Ciertamente nuestras cifras son tentativas pero no dejan de lado una realidad muy aproximada: el Poder Judicial maneja un estimado de 30\% de carga estimatoria de procesos constitucionales y de aquello que llega al Tribunal Constitucional, la carga de sentencia estimatoria, en un esquema de razonabilidad, igualmente camina en línea similar a estos estándares, es decir, un 30\% de casos merecen decisiones estimatorias por parte del alto Tribunal. En consecuencia, sí se justifica una justicia constitucional especializada que a su vez pueda significar una desconcentración de la carga procesal, en parte, ante el Tribunal Constitucional.

\section{Efectos de la ausencia de jueces constitucionales}

Si no existen jueces constitucionales, jueces ordinarios, en adición a su funciones, seguirán conociendo procesos constitucionales, cuyos patrones demandan un plus de interpretación atendiendo a contenidos de moralidad, tan caros frente a simples contenidos de juridicidad.

$\mathrm{Si}$ no optamos por ninguna alternativa de justicia constitucional especializada, solamente jueces civiles, en adición a sus funciones, y jueces penales, de igual forma y en modo adicional a sus funciones especializadas, seguirán resolviendo cuestiones constitucionales de singular relevancia en procesos de amparo y habeas corpus, respectivamente. En la misma forma, Salas Civiles y Penales cuya naturaleza de conocimiento es distinta, seguirán resolviendo, en adición a sus recargadas tareas, casos propios de la justicia constitucional.

No es propio negar que estos jueces puedan dilucidar estas controversias constitucionales, de seguro el nivel de competencias del juez civil o penal puede verse reforzado a través de un conocimiento más profundo de los derechos fundamentales conforme cada caso vaya demandando exigencias específicas de redimensionamiento de los derechos fundamentales, mas es categórico afirmar que 
es una exigencia material y contemporánea construir un conjunto de preceptos necesarios para el manejo de una judicatura constitucional especializada.

Pautas como el manejo de procesos sin etapa probatoria, o bien la actuación solo de pruebas documentarias para acreditar la grave vulneración de un derecho fundamental, o bien el pauteo de constatación de la ilegitimidad del acto lesivo, o de las omisiones que este involucra, exigen por cierto un modus operandi que puede ser resuelto en mejor forma bajo la dirección de jueces constitucionales con competencias propias.

Dejar de lado la creación o reinstalación de estos órganos especializados conlleva, igualmente, la percepción del justiciable respecto a que un juez con otra especialidad en el Derecho resuelve su caso. Ello en principio no es propiamente negativo en tanto ocurre en numerosas localidades a nivel nacional con los jueces mixtos, quienes resuelven todas las materias dado la reducida circunscripción geográfica que les corresponde. Y sin embargo, como antes hemos anotado, el Derecho es evolución, el Derecho es perfeccionamiento, el Derecho es la consolidación de las especialidades y a estas tareas deben orientarse las políticas públicas de los órganos de gobierno.

De igual forma, la carencia de estos órganos jurisdiccionales especializados en materia constitucional origina que nuestro país pierda una oportunidad extraordinaria de afianzamiento en el Derecho Constitucional en el ámbito latinoamericano. Si bien Colombia tiene un bien ganado prestigio por la fortaleza académica de los magistrados de su Corte Constitucional desde la Carta de 1991 de ese país, Perú sin embargo se consolidó con la dación de un Código Procesal Constitucional a nivel país desde 2004. Y a su turno, la existencia de jueces constitucionales, desde la perspectiva de este Código, significó una importante proyección de Perú en el escenario comparado de los derechos fundamentales. A pesar de ello, poco se ha avanzado a nivel de órganos de gobierno en esta tarea de consolidar órganos especializados en materia constitucional.

Creemos pues que no se debe perder esa oportunidad de ampliar las dimensiones en positivo de una defensa procedimental adecuada de los derechos fundamentales. Con un Código Procesal especializado y determinados órganos estaduales para la defensa de los derechos fundamentales, Perú puede posicionarse en el más alto lugar de defensa del Estado constitucional y esa es una tarea de retos, que exige ser retomada. 


\section{Casos especiales de justicia constitucional especializada}

El Juzgado Constitucional en Ayacucho y la Sala Constitucional de Lambayeque, ${ }^{21} \mathrm{el}$ primero en el sur andino, y el segundo órgano en la costa norte del país, representaron una primera experiencia interesante de especialización en competencias constitucionales propiamente dichas.

Con facultad para conocer procesos constitucionales de la libertad- habeas corpus, amparo, habeas data y cumplimiento- dichos órganos funcionaron hasta el año 2014, cuando por una decisión del Consejo Ejecutivo del Poder Judicial, ${ }^{22}$ se optó por reconvertir dichas unidades a despachos en materia laboral.

Si bien la justificación fue la de necesidades de servicio, ciertamente se paralizó un importante trabajo de campo y de especialización en dichas materias, bajo la justificación de atender la importante carga del Poder Judicial en materia laboral.

Aunque no es el objetivo de nuestro estudio, la existencia de carga laboral considerable exige más un replanteamiento de políticas públicas antes que atender cuestiones de emergencia con la creación de nuevos órganos jurisdiccionales, o bajo el segundo esquema aún más complejo de la reconversión. En efecto, este último camino, bastante frecuente en los últimos años, ha significado desatender una especialidad para atender otra, y ello ha sucedido bajo la sola justificación de una carga procesal ingente en materia laboral.

A juicio nuestro, no ha constituido la decisión de reconvertir órganos jurisdiccionales del Consejo Ejecutivo del Poder Judicial, la alternativa más ponderada, pues deja sin efecto el camino inicialmente trazado por la especialidad constitucional para atender contextos de emergencia. A este respecto, nuestra realidad nacional arroja una definición nominal de carga procesal, dado el número de procesos similares, de criterios homogenizados y de necesidad de regular normas de descongestión. Por ello, las opciones de reconversión de órganos jurisdiccionales no han ayudado a la consolidación de especialidades, y de suyo, la materia constitucional exige competencias específicas pues atañen al valor axiológico de los derechos tutelados por la Carta Fundamental.

\section{Una visión de los jueces constitucionales en el Derecho Comparado}

La tendencia prevalente en el Derecho Comparado es la de consolidación de Cortes Constitucionales autónomas y Tribunales constitucionales independientes. Entre

21 La Sala Constitucional de Lambayeque inició sus funciones el 12 de abril de 2006, a mérito de la Resolución 009-2006-CE-PJ, de fecha 26 de enero de 2006. La misma resolución crea un Juzgado Especializado en Derecho Constitucional, en la sede de la Corte Superior de Justicia de Ayacucho.

22 A través de la Res. Adm. N 415-2014-CEPJ del 10 de diciembre de 2014, el Consejo Ejecutivo del Poder Judicial de Perú desactiva la Sala Constitucional de Lambayeque, y la reconvierte en una Sala Laboral a partir del 1 de enero de 2015, dejando de lado una especialidad en el servicio de impartición de justicia. 
estos órganos jurisdiccionales destacan el Tribunal Constitucional Federal alemán,,23 ciertamente una de las Cortes más activas desde 1951, año de su instalación, en consolidar los conceptos materiales de contenido esencial de los derechos fundamentales y de Estado Democrático y Social de Derecho.

De la misma forma, el Tribunal Constitucional español ${ }^{24}$ ha sentado importante jurisprudencia desde la Carta española de 1978, marcando la tendencia evolutiva de los derechos fundamentales. España constituye referencia necesaria en temas constitucionales por la cercanía a nuestro idioma y porque constituye un bastión de construcción conceptual desde la Academia.

Por otro lado, la Corte Constitucional italiana ${ }^{25}$ y el Consejo Constitucional de Francia ${ }^{26}$ representan, igualmente, aunque bajo distintos rasgos en relación a los patrones de nuestra jurisprudencia, arquetipos de justicia constitucional autónoma como ejemplos de Cortes ajenas al Poder Judicial.

En el lado sur de nuestro continente, la Corte Constitucional de Colombia ${ }^{27}$ representa un ejemplo de consolidación en la interpretación constitucional desde 1991.

La nota distintiva en todos estos casos es, en propiedad, un ejercicio de defensa de los derechos fundamentales, en instancia de cierre, por parte de estas Cortes Constitucionales, reservándose en esos mismos ordenamientos, al igual que en el caso peruano, la protección inicial de los derechos constitucionales al Poder Judicial.

Es aquí entonces donde nuestra propuesta adquiere contenido material pues se trata precisamente de que esos bastiones de defensa de los derechos iusfundamentales, no

23 El Tribunal Constitucional Federal alemán se denomina también Bundesverfassungsgeridht, con sede en Karlsruhe, Baden Wurtemberg. Tiene la función de control de constitucionalidad de las leyes en la República Federal Alemana. Está compuesto por dos senados, cada uno de los cuales tiene ocho miembros, de los que cuatro son elegidos por un comité del Bundestag y otros cuatro por el Bundesrat, siempre con mayoría de dos tercios.

24 Creado por la Constitución Española del 27 de diciembre de 1978. Se compone de 12 miembros.

25 La Corte Constitucional Italiana tiene la función de control de constitucionalidad de las leyes en Italia. Se compone de quince jueces, nombrados por terceras partes: por el Presidente de la República, por el Parlamento en sesión conjunta de ambas Cámaras, y por las supremas magistraturas ordinarias y administrativas. O sea, intervienen en su generación los órganos de los tres poderes del Estado.

26 La Constitución Francesa de 1958 creó el Consejo Constitucional, órgano jurisdiccional cuya función esencial es verificar la constitucionalidad de las leyes. El art. 56 de la Constitución de la $5^{\text {a }}$ República Francesa dice que "el Consejo Constitucional comprenderá nueve miembros, cuyo mandato durará nueve años y no será renovable", o sea, que no tienen derecho a reelección. Asimismo, estos consejeros se renuevan por tercios cada tres años.

27 Con una representatividad importante en América del Sur, la Corte Constitucional de Colombia vela por la integridad y la supremacía de la Constitución. Fue creada por la Constitución de Colombia de 1991 e instalada por primera vez el 17 de febrero de 1992. En la actualidad, cuenta con nueve magistrados, que son elegidos para periodos de ocho años por el Senado, a partir de las ternas enviadas por el Presidente de la República, la CorteSuprema de Justicia y el Consejo de Estado. 
solo sea tarea de los órganos de cierre, en su mayoría Tribunales de alto rango, sino que en propiedad se vean ampliadas las competencias de los jueces de los Poderes Judiciales, para dar respuesta, con facultades reforzadas, a las pretensiones que demanden restitución por la afectación grave de los derechos en pugna.

Bajo esta pauta, la labor de los jueces constitucionales del Poder Judicial cumplirá la función de complementar las líneas directrices de los altos Tribunales. Es pertinente precisar la atingencia antes enunciada: el desarrollo de los contenidos de moralidad de los derechos fundamentales, demandan una visión mucho más amplia, que sin afectar los contenidos de juridicidad de los derechos, puedan reducir el margen de indeterminación de los derechos fundamentales, reducir su rango de conceptos jurídicos indeterminados, y asignarles contenidos no solo vigentes sino también válidos, es decir de compatibilidad con la Norma de Normas, a estos derechos.

¿Pueden desarrollar esta compleja tarea los jueces de otras especialidades? En principio sí, pero de la misma forma, es razonable el aserto de que la especialidad del juez constitucional a dedicación exclusiva, redunda en una posibilidad de mejor respuesta frente a las vulneraciones ilegítimas de los derechos fundamentales.

\section{A modo de conclusión}

a) Creemos que es posible un replanteamiento de la actual política judicial en materia de jueces constitucionales y es viable la reinstalación de órganos constitucionales a dedicación exclusiva: el Derecho asume una tendencia de especialización cada vez más creciente y ésa es una justificación de fondo para este estudio.

b) El desarrollo natural del Derecho Procesal asume una simbiosis estrecha entre Derecho y especialización. El juez debe apuntar a dejar de ser todista para convertirse en un especialista de la materia. De ser así, el resultado ha de ser apreciable en la respuesta técnica que es la sentencia especializada, la cual exige un juez profundamente conocedor de la materia sometida a su examen.

c) No ha parecido, de esa forma, un ejercicio de lo más acertado el número considerable de reconversiones de órganos jurisdiccionales producidas en nuestro país. Desde una fría perspectiva de evaluación, constituye solo una respuesta de emergencia frente al contexto de alta carga procesal, y de paso, representa un serio retroceso en los esfuerzos de especialización de los jueces. No resulta el mejor escenario que atender especialidades por cuestiones de emergencia, deje sin efecto el camino de formación profesional de los jueces en el desarrollo de sus competencias.

d) De esa forma, un replanteamiento de política pública de creación de órganos jurisdiccionales constitucionales, se condice con la exigencia del deber 
especial de protección de los derechos fundamentales, que perfila la doctrina constitucional. Es un imperativo categórico que los órganos de dirección del Poder Judicial no pueden soslayar.

\section{Referencias bibliográficas}

\section{Libros}

ZAGREBELSKY, Gustavo. (2008) Principios y votos. El Tribunal Constitucional y la política. Traducción de Manuel Martínez Neira. España. Mínima Trotta.

\section{Artículos en revistas}

GARGARELLA, Roberto (1997). "La dificultad de defender el control constitucional de las leyes." Isonomía. No. 6. Abril.

HARO, Ricardo."El control de constitucionalidad comparado y el rol paradigmático de las cortes y tribunales constitucionales". En Anuario de Derecho Constitucional Latinoamericano, n. ${ }^{\circ} 20041,2004$.

ZAGREBELSKY, Gustavo. (2008) "El juez constitucional en el siglo XXI". Ponencia presentada en el I Congreso Internacional de Justicia Constitucional y V Encuentro Iberoamericano de Derecho Procesal Constitucional, celebrado en Cancún, México, del 14 al 17 de mayo de 2008. Revista Iberoamericana de Derecho Procesal Constitucional núm. 10, julio-diciembre 2008.

ZAGREBELSKY, Gustavo. "¿Qué es ser juez constitucional?". Discurso pronunciado por Gustavo Zagrebelsky, el 22 de abril de 2006 en Roma, con motivo del 50 aniversario de la Corte Constitucional italiana. Traducción de Miguel Carbonell. Universidad Nacional Autónoma de México UNAM. Consulta: 07 de abril de 2016. Disponible en file:///C:/Users/usuario/Downloads/DialnetQueEsSerJuezConstitucional-2292042\%20(1).pdf 